\title{
Linfuranone $A$, a new polyketide from plant-derived Microbispora sp. GMKU 363
}

\author{
Chantra Indananda ${ }^{1,2}$, Yasuhiro Igarashi ${ }^{3}$, Megumi Ikeda ${ }^{4}$, Tsutomu Oikawa ${ }^{4}$ and Arinthip Thamchaipenet ${ }^{1,5}$
}

The Journal of Antibiotics (2013) 66, 675-677; doi:10.1038/ja.2013.67; published online 3 July 2013

Keywords: endophyte; furanone; Microbispora; polyketide

Actinomycetes are well-known producers of an enormous variety of secondary metabolites, many of which have beneficial applications in the field of medicine and agriculture. More recently, endophytic actinomycetes residing in plants revealed the potential sources of biodiversity carrying a variety of bioactive metabolites and acting as potential biocontrol agents. ${ }^{1-3}$ Particularly, endophytic actinomycetes isolated from tropical plants have been examined to possess significant biosynthetic potential, particularly polyketide synthase and nonribosomal peptide synthetase genes. ${ }^{4}$ We have recently reported a new polyketide compound from an endophytic actinomycete isolated from a Thai medicinal plant collected at the Eastern Botanical Garden (Khao Hin Son), Chachoengsao province, Thailand. ${ }^{5}$ Here, we now report a new furanone-containing polyketide, linfuranone A (Figure 1), produced by an endophytic actinomycete isolated from a Thai medicinal plant collected at the same location.

An endophytic Microbispora sp. GMKU363 was isolated from a root of Thai medicinal plant 'Lin Ngu Hao' (Clinacanthus siamensis Bremek.) according to the reported protocol. ${ }^{6}$ The strain was identified as a member of the genus Microbispora on the basis of 99.9\% 16S ribosomal RNA gene sequence identity (1387 nucleotides; GenBank accession number GU459171) with the Microbispora mesophila JCM $3151^{\mathrm{T}}$ type strain (accession number AF002266).

Strain GMKU363 was cultured on Bn-2 slant agar medium consisting of soluble starch $0.5 \%$, glucose $0.5 \%$, meat extract (Kyokuto Pharmaceutical Industrial Co., Ltd., Tokyo, Japan) $0.1 \%$, yeast extract (Difco Laboratories, Detroit, MI, USA) 0.1\%, NZ-case (Wako Pure Chemical Industries, Ltd., Osaka, Japan) $0.2 \%, \mathrm{NaCl} 0.2 \%, \mathrm{CaCO}_{3}$ $0.1 \%$, agar $1.5 \%$ and was inoculated into $500-\mathrm{ml} \mathrm{K}-1$ flasks each containing $100 \mathrm{ml}$ of the $\mathrm{V}-22$ seed medium ( $\mathrm{pH} 7.0$ ) consisting of soluble starch $1 \%$, glucose $0.5 \%$, NZ-case $0.3 \%$, yeast extract $0.2 \%$, triptone (Difco Laboratories) $0.5 \%, \mathrm{~K}_{2} \mathrm{HPO}_{4} 0.1 \%, \mathrm{MgSO}_{4} \cdot 7 \mathrm{H}_{2} \mathrm{O}$ $0.05 \%$ and $\mathrm{CaCO}_{3} 0.3 \%$. The cultures were cultivated on a rotary shaker (200 r.p.m.) at $30^{\circ} \mathrm{C}$ for 4 days. The seed culture $(3 \mathrm{ml})$ was transferred into 500-ml K-1 flasks each containing $100 \mathrm{ml}$ of the A-11M production medium $(\mathrm{pH} 7.0$ ) consisting of soluble starch $2.5 \%$, glucose $0.2 \%$, yeast extract $0.5 \%$, polypeptone (Wako Pure Chemical Industries, Ltd.) $0.5 \%, \mathrm{NZ}$-amine $0.5 \%, \mathrm{CaCO}_{3} 0.3 \%$ and Diaion HP-20 (Mitsubishi Chemical Co.) 1\%. The cultures inoculated in flasks were cultured on a rotary shaker $\left(200\right.$ r.p.m.) at $30^{\circ} \mathrm{C}$ for 6 days, and the whole culture broth was extracted with $100 \mathrm{ml}$ of 1butanol on each flask by shaking for an additional hour. The organic layer was evaporated to give $3.0 \mathrm{~g}$ of crude extract from $1.5 \mathrm{l}$ of culture. The crude extract $(3.0 \mathrm{~g})$ was subjected to silica gel column chromatography with a step gradient of $\mathrm{CHCl}_{3}-\mathrm{MeOH}$ (1:0, 20:1, 10:1, 4:1, $2: 1,1: 1$ and $0: 1 \mathrm{v} / \mathrm{v})$. The concentration of the fraction eluted with a 2:1 mixture of $\mathrm{CHCl}_{3}-\mathrm{MeOH}$ provided $0.23 \mathrm{~g}$ of dark viscous oil, which was further purified by preparative HPLC (Cosmosil AR-II, San Diego, CA, USA, $250 \times 10 \mathrm{~mm}^{2}$ ) using $30 \% \mathrm{MeCN}$ in distilled water at $4 \mathrm{ml} \mathrm{min}{ }^{-1}$ to give linfuranone $\mathrm{A}\left(2.0 \mathrm{mg}, t_{\mathrm{R}}=12.1 \mathrm{~min}\right)$.

Linfuranone A (Figure 1 ) was obtained as an optically active $\left([\alpha]_{\mathrm{D}}{ }^{22}\right.$ $-9.9(c 0.16, \mathrm{MeOH})$ ), colorless and amorphous compound that gave an $[\mathrm{M}+\mathrm{Na}]^{+}$peak at $\mathrm{m} / z 417.2257$ in the high resolution electrospray ionization time-of-flight mass spectrometry appropriate for a molecular formula of $\mathrm{C}_{22} \mathrm{H}_{34} \mathrm{O}_{6}$, (calculated for $\mathrm{C}_{22} \mathrm{H}_{34} \mathrm{O}_{6} \mathrm{Na}$, 417.2248), which was consistent with the ${ }^{1} \mathrm{H}$ and ${ }^{13} \mathrm{C}$ NMR data (Table 1). The IR spectrum of linfuranone A showed absorption bands for hydroxyl $\left(3333 \mathrm{~cm}^{-1}\right)$ and carbonyl $\left(1691 \mathrm{~cm}^{-1}\right)$ functionalities. The UV spectrum showed absorption maxima at $282(\varepsilon 23600)$ and 232 ( $\varepsilon$ 75300) in $\mathrm{MeOH} .{ }^{13} \mathrm{C} \mathrm{NMR}$ and HMQC spectral data confirmed the presence of 22 carbons, which were assigned to two oxygenated-quaternary $\mathrm{sp}^{2}$ carbons, seven olefinic carbons (five are proton-bearing), one quaternary $\mathrm{sp}^{3}$ carbon, four $\mathrm{sp}^{3}$ methines (three are oxygen-bearing), three $\mathrm{sp}^{3}$ methylenes and five methyl carbons.

Analysis of the COSY spectrum led to the identification of four proton-bearing fragments, $\mathrm{H}-17-\mathrm{H}-19, \mathrm{H}-15 / \mathrm{H}-14 / \mathrm{H}-21, \mathrm{H}-12 / \mathrm{H}-13$ and $\mathrm{H}-6-\mathrm{H}-11$ (Figure 1). HMBC correlations were detected from the

${ }^{1}$ Faculty of Science, Actinobacteria Research Unit, Department of Genetics, Kasetsart University, Bangkok, Thailand; ${ }^{2}$ Faculty of Science, Department of Biology, Burapha University, Chonburi, Thailand; ${ }^{3}$ Biotechnology Research Center, Toyama Prefectural University, Toyama, Japan; ${ }^{4}$ Department of Nutritional Biochemistry, School of Nutrition and Dietetics, Kanagawa University of Human Services, Kanagawa, Japan and ${ }^{5}$ Center for Advanced Studies in Tropical Natural Resources, National Research University-Kasetsart University (CASTNAR, NRU-KU), Bangkok, Thailand

Correspondence: Dr A Thamchaipenet, Faculty of Science, Actinobacteria Research Unit, Department of Genetics, Kasetsart University, 50 Ngamwongwan Road, Chatuchak, Bangkok 10900, Thailand.

E-mail: arinthip.t@ku.ac.th

Received 21 March 2013; revised 12 May 2013; accepted 23 May 2013; published online 3 July 2013 

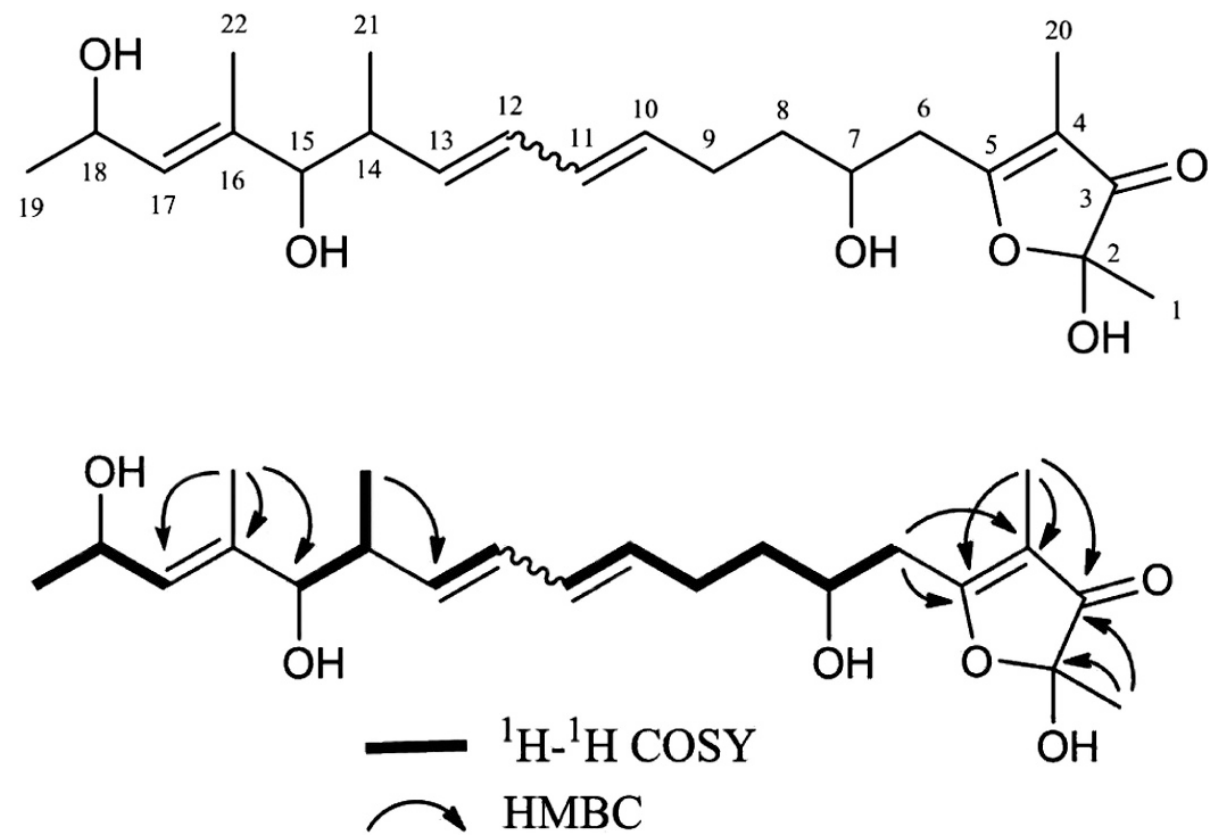

Figure 1 Structure of linfuranone $A,{ }^{1} \mathrm{H}-{ }^{1} \mathrm{H}$ COSY and key HMBC correlations.

Table $1{ }^{1} \mathrm{H}$ and ${ }^{13} \mathrm{C}$ NMR data for linfuranone $\mathrm{A}$ in $\mathrm{CD}_{3} \mathrm{OD}$

\begin{tabular}{|c|c|c|c|}
\hline No & $\delta_{C}{ }^{a}$ & $\delta_{H}$ mult $(\mathrm{J} \text { in } \mathrm{Hz})^{\mathrm{b}}$ & $H M B C^{b, c}$ \\
\hline 1 & $22.3 / 22.4, \mathrm{CH}_{3}$ & $1.43 / 1.44, \mathrm{~s}$ & 2,3 \\
\hline 2 & 104.37/104.39, qC & & \\
\hline 3 & 205.5, qC & & \\
\hline 4 & 110.3, qC & & \\
\hline 5 & 187.2, qC & & \\
\hline \multirow[t]{2}{*}{6} & $38.5, \mathrm{CH}_{2}$ & $2.65, \mathrm{~m}$ & $4,5,7,8$ \\
\hline & & $2.72, \mathrm{~m}$ & $4,5,7,8$ \\
\hline 7 & $69.6, \mathrm{CH}$ & $3.96, m$ & \\
\hline 8 & $38.2 / 38.3, \mathrm{CH}_{2}$ & $1.61, \mathrm{~m}$ & $7,9,10$ \\
\hline \multirow[t]{2}{*}{9} & $29.9, \mathrm{CH}_{2}$ & $2.18, \mathrm{~m}$ & $7,8,10$ \\
\hline & & $2.24, \mathrm{~m}$ & $7,8,10$ \\
\hline 10 & $132.74 / 132.79,{ }^{\mathrm{d}} \mathrm{CH}$ & $5.59, \mathrm{~m}$ & 11,12 \\
\hline 11 & $132.68 / 132.70,{ }^{\mathrm{d}} \mathrm{CH}$ & $6.06, \mathrm{~m}$ & \\
\hline 12 & $132.00 / 132.02, \mathrm{CH}$ & $6.06, \mathrm{~m}$ & \\
\hline 13 & $136.3 / 136.4, \mathrm{CH}$ & $5.58, \mathrm{~m}$ & 11,12 \\
\hline 14 & $41.8, \mathrm{CH}$ & $2.31, \mathrm{~m}$ & $13,15,21$ \\
\hline 15 & $83.1, \mathrm{CH}$ & $3.63, d(8.4)$ & $13,14,17,21,22$ \\
\hline 16 & 138.0, qC & & \\
\hline 17 & $133.5, \mathrm{CH}$ & $5.35, d(8.4)$ & 18,22 \\
\hline 18 & $65.2, \mathrm{CH}$ & $4.56, \mathrm{dq}(8.4,6.4)$ & 16 \\
\hline 19 & $22.9, \mathrm{CH}_{3}$ & $1.19, \mathrm{~d}(6.4)$ & 17,18 \\
\hline 20 & $6.0, \mathrm{CH}_{3}$ & $1.67, \mathrm{~s}$ & $3,4,5$ \\
\hline 21 & $18.0, \mathrm{CH}_{3}$ & $0.86, d(7.0)$ & $13,14,15$ \\
\hline 22 & $11.6, \mathrm{CH}_{3}$ & $1.64, d(1.1)$ & $15,16,17$ \\
\hline
\end{tabular}

aRecorded at $100 \mathrm{MHz}$

bRecorded at $500 \mathrm{MHz}$

cHMBC correlations are from proton(s) stated to the indicated carbon.

dInterchangeable signals.

singlet methyl protons $\mathrm{H}-22$ to C-15, C-16 and C-17, establishing the connectivity from C-17 to C-15 and the methyl substitution at the quaternary $\mathrm{sp}^{2}$ carbon $\mathrm{C}-16$. This fragment was connected to the $\mathrm{H}-12 / \mathrm{H}-13$ fragment on the basis of an HMBC correlation from $\mathrm{H}-21$ to $\mathrm{C}-13$, providing an eight-carbon fragment bearing two oxygen substitutions at C-15 and C-18. The last COSY-defined fragment was connected to the $\alpha, \beta$-unsaturated ketone substructure bearing an oxygen substitution at $\beta$-position on the basis of a series of HMBC correlations from $\mathrm{H}-6$ to $\mathrm{C}-4$ and $\mathrm{C}-5$, and from a vinyl methyl $\mathrm{H}-20$ to C-3, C-4, and C-5. The carbonyl carbon C-3 was correlated with $\mathrm{H}-1$, which also showed a correlation to the oxygenated carbon C-2 ( $\delta$ 104.4), establishing the attachment of the two-carbon fragment C-1/C-2 to C-3. The chemical shift of C-2 was suggestive of the bonding of two oxygen atoms to this carbon. Finally, considering of the molecular formula and the remaining unsaturation degree provided the connectivity between $\mathrm{C}-11$ and $\mathrm{C}-12$, and the placement of an oxygen atom between C-2 and C-5 to establish this molecule as a new member of furanone-containing polyketides. $E$ configuration for the double bond between C-16 and C-17 was confirmed by NOEs between $\mathrm{H}-18$ and $\mathrm{H}-22$, and $\mathrm{H}-15$ and $\mathrm{H}-17$. The geometry of C-10/ C-11 and C-12/C-13 double bonds could not be assigned due to the proton signal overlapping. As two possible configurations exist at the C-2 hemiketal carbon, two signals corresponding to the two diastereomers were observed for $\mathrm{H}-1$ and several carbons (Table 1). Absolute stereochemistry of linfuranone A is under investigation.

Linfuranone $A$ is a relatively rare 3-furanone derived from polyketide, with a hemiketal at C-2 and an unsaturated alkyl chain at C-5. There are a few known structurally close metabolites isolated from Streptomyces spp., which are E837, E492, E975 and actinofuranones A and B. ${ }^{7,8}$ Further related structures are not from actinobacterial origin, but were isolated from myxobacteria, fungi and marine molluscs. ${ }^{9-13}$ E837, E492 and E975 exhibited inhibition against helminth NADH-fumarate reductase and bovine heart NADH oxidase, ${ }^{7}$ whereas actinofuranones had no display of biological activity. ${ }^{8}$ Biological screening of linfuranone $\mathrm{A}$ in diverse bioassays indicated that this compound was active in an assay designed to screen antidiabetic and antiatherogenic activities using mouse ST-13 pre-adiopocytes. ${ }^{14}$ By the treatment with $50 \mu \mathrm{m}$ linfuranone A, $47 \%$ of pre-adipocytes were differentiated into the matured adipocytes and 
accumulated the lipid droplets. Linfuranone A displayed no appreciable activities in antimicrobial and cytotoxic assays.

\section{ACKNOWLEDGEMENTS}

CI was awarded PhD scholarship from the Commission on Higher Education, Ministry of Education, Thailand. This study was supported by Thailand Research Fund under grant number DBG5480002 and Faculty of Science, Burapha University.

1 El-Tarabily, K. A. \& Sivasithamparam, K. Non-streptomycete actinomycetes as biocontrol agents of soil-borne fungal plant pathogens and as plant growth promoters. Soil Biol. Biochem. 38, 1505-1520 (2006).

2 Qin, S., Xing, K., Jiang, J. H., Xu, L. H. \& Li, W. J. Biodiversity, bioactive natural products and biotechnological potential of plant-associated endophytic actinobacteria. Appl. Microbiol. Biotechnol. 89, 457-473 (2011).

3 Rungin, S. et al. Plant growth enhancing effects by a siderophore-producing endophytic streptomycete isolated from a Thai jasmine rice plant (Oryza sativa L. cv. KDML105). Antonie Van Leeuwenhoek 102, 463-472 (2012).

4 Janso, J. E. \& Carter, G. T. Biosynthetic potential of phylogenetically unique endophytic actinomycetes from tropical plants. Appl. Environ. Microbiol. 76, 4377-4386 (2010).

5 Igarashi, Y. et al. Maklamicin, an antibacterial polyketide from an endophytic Micromonospora sp. J. Nat. Prod. 74, 670-674 (2011).
6 Indananda, C. et al. Actinophytocola oryzae gen. nov., sp. nov., isolated from the roots of Thai glutinous rice plants, a new member of the family Pseudonocardiaceae. Int. J. Syst. Evol. Microbiol. 60, 1141-1146 (2010).

7 Banskota, A. H. et al. Isolation and identification of three new 5-alkenyl-3,3(2H)furanones from two Streptomyces species using a genomic screening approach. J. Antibiot. 59, 168-176 (2006).

8 Cho, J. Y. et al. Actinofuranones A and B, polyketides from a marine-derived bacterium related to the genus Streptomyces (Actinomycetales). J. Nat. Prod. 69, 425-428 (2006).

9 Capon, R. J. \& Faulkner, D. J. Metabolites of the pulmonate Siphonaria lessoni. J. Org. Chem 49, 2506-2508 (1984).

10 Cimino, G., Sodano, G. \& Spinella, A. New propionate-derived metabolites from Aglaja depicta and from its prey Bulla striate (Opisthobranch Molluscs). J. Org. Chem. 52, 5326-5331 (1987).

11 Kuroda, K. et al. As-183, a novel inhibitor of acyl-CoA-cholesterol acyltransferase produced by Scedosporium sp. SPC-15549. J. Antibiot. 46, 1196-1202 (1993).

12 Kunze, B., Reichenbach, H., Müller, R. \& Höfle, G. Aurafuron A and B, new bioactive polyketides from Stigmatella aurantiaca and Archangium gephyra (Myxobacteria). Fermentation, isolation, physico-chemical properties, structure and biological activity. J. Antibiot. 58, 244-251 (2005).

13 Bromley, C. L., Popplewell, W. L., Pinchuck, S. C., Hodgson, A. N. \& Davies-Coleman, M. T. Polypropionates from the South African marine mollusk Siphonaria oculus. J. Nat. Prod. 75, 497-501 (2012).

14 Kunimasa, K. et al. Identification of nobiletin, a polymethoxyflavonoid, as an enhancer of adiponectin secretion. Bioorg. Med. Chem. Lett. 19, 2062-2064 (2009). 